\title{
Evaluating the Performance of Absolute RSSI Positioning Algorithm-Based Microzoning and RFID in Construction Materials Tracking
}

\author{
M. Truijens, ${ }^{1}$ X. Wang, ${ }^{2,3}$ H. de Graaf, ${ }^{4}$ and J. J. Liu ${ }^{5}$ \\ ${ }^{1}$ Woodside Energy Ltd., School of Built Environment, Curtin University, Perth, WA 6845, Australia \\ ${ }^{2}$ Curtin-Woodside Oil, Gas \& LNG Construction and Project Management, Australasian Joint Research Centre for \\ Building Information Modelling (BIM), Curtin University, Perth, WA 6845, Australia \\ ${ }^{3}$ Department of Housing and Interior Design, Kyung Hee University, Seoul 130-701, Republic of Korea \\ ${ }^{4}$ Industrial Automation Group MD, Joondalup Business Park, Perth, WA 6027, Australia \\ ${ }^{5}$ College of Science, China University of Petroleum, Beijing 102249, China
}

Correspondence should be addressed to X. Wang; xiangyu.wang@curtin.edu.au and J. J. Liu; liujj@cup.edu.cn

Received 24 February 2014; Accepted 27 April 2014; Published 21 May 2014

Academic Editor: Changzhi Wu

Copyright (C) 2014 M. Truijens et al. This is an open access article distributed under the Creative Commons Attribution License, which permits unrestricted use, distribution, and reproduction in any medium, provided the original work is properly cited.

High accuracy of construction materials tracking with radio frequency identification technology (RFID) is challenging to achieve. The microzoning method consists essentially of an absolute received signal strength indication (RSSI) positioning algorithm on the basis of measuring the distance of tag from antennas base. In this paper, we analyse and examine the effects of microzoning method on the performance of RFID tags. A system was set up whereby RFID tags and antennas with the microzoning method were developed and studied. The performance of the tag antennas was studied with the practical read-range measurements. The study results showed that this absolute algorithm worked reliably and was suitable for RFID applications requiring identification of positions of onsite materials and components. The results also showed that the algorithm achieved a large read range and high accuracy. The study investigates the RFID solutions for Australian LNG (liquefied natural gas) industry and was initiated by the collaboration between Woodside Energy, Curtin University, and Industrial Automation Group Pty Ltd.

\section{Introduction}

Accurate location of LNG (liquefied natural gas) plant assets like piping, valve, and equipment is a major issue in Australian LNG industry. The current methods used to pinpoint the location of set-in-place assets are useful in varying degrees. Thus far, unfortunately, none of these methods gives the degree of accuracy. That is, the current methods are not able to provide accurate and comprehensive data on the location of each asset. For example, in LNG supply chain, it is normally a challenging task to efficiently identify, track, and position pipes as many of the present-day applications are still using the paper-based methods. The problems encountered in terms of the paper-based material tracking are getting late deliveries, missing components, and incorrect installations, which result in additional labor and material costs. In the current LNG practice, pipe installation activities at the construction site normally need workers to search paper instructions, on which the destination and delivery information are stored. Once the instructions are produced, they are transferred to the storage area and archived as the layout plan for assembly workers to retrieve information from. If the workers cannot locate the relevant information in time, an extended search needs to be carried out at the construction site to locate the missing component [1].

To address these issues, radio frequency identification technology (RFID) which uses radio frequency waves to transmit data between readers and tags is widely adopted. RFID automatically streamlines the identification and acquisition of data, without the need for direct contact between 
readers and tags. A typical RFID system includes an antenna, a transceiver (RFID reader), and a transponder (radio frequency tag) [2]. The antenna generates an electromagnetic zone where the tag detects the activation signal and responds by sending the stored data from its memory through radio frequency waves.

Types of RFID tags can be active, passive, or battery assisted passive (BAP) [3]. The active tags are equipped with built-in batteries and work on a "tag-talks-first" principle. Thus, their activation is not dependent on the RFID reader, and the tags periodically transmit their ID signal. The active tags can be detected over a long distance (>100 m) [4]. The passive tags, however, require an RFID reader to generate the activated electromagnetic field while the tags can only be detected in a short range (around $10-15 \mathrm{~m}$ maximum) [4]. The RFID tags used in the study belong to BAP, a new classification of RFID. BAP is recognized in a new international standard of RFID technology: ISO/IEC 180006:2010 Class 3 [5]. The BAP tags do not transmit their ID, but the tags "backscatter" the reader's signal with their ID. The battery in BAP is used only for powering the chip (and hence amplifying the backscattered signal). The BAP tags provide the same performance $(>100 \mathrm{~m})$ as the active tags but closer to the cost of the passive tags. Moreover, within 3-4 years the BAP technology does not need the battery to be replaced inside the tags, whereas in case of the active tags, the battery needs to be replaced frequently (order of days-weeks). Therefore the BAP tags are scalable in terms of cost and can be used throughout the entire LNG plant to cater for millions of materials and components search. Apart from storing tag IDs, BAP tags also support $64 \mathrm{~kb}$ rewritable memory in which users can read/write data.

The RFID reader can be portable or fixed. The portable readers come along with an antenna and can be held like a hand gun. The portable readers are also equipped with a wireless module through which they can communicate the tag information to the server. The fixed readers need to be connected to external patch antennas that can be mounted on walls or clamped on poles. The fixed readers communicate through an Ethernet connection to the server. Fiber optic cabling or Wi-Fi can be used for connecting hundreds of readers to a server. This study uses both portable and fixed readers to increase giving the flexibility of the RFID system.

\section{Relevant Work}

RFID has been widely deployed in variety of applications, such as logistics [6], mining [7], air cargo [8], hospitals [9], museums [10], retailing [11-13], and waste management [14]. RFID has recently attracted significant attention in construction areas such as material tracking (e.g., structural steel members), quality control, equipment monitoring and inspection, and maintenance [15-18].

Ren et al. [19] identify that poor materials management typically incurs low construction productivity, cost overrun, and delays. They further specify major contributors to such problems, namely, lack of active, accurate, and integrated information flow. Motamedi et al. [20] use permanently attached tags to allow different users to share and handle lifecycle information.

Most of the research in investigating the technical capacity of RFID is focused upon the hardware study of tags and antennas such as RFID tags and antennae [21, 22]. There has been very few research on investigating the algorithm, methods, and theories on RFID implementation and evaluation that can be applied in practice for practitioners. Zhou and Shi [23] propose an algorithm based on a signal propagation model to get the accurate location information of objects. A multilateration method is formulated as the kernel of the algorithm to maximize the accuracy of distance measurements between RFID tags and readers. Song et al. [24] present a method to extend the use of current RFID technology in tracking the precise location of tagged materials on construction sites. The combination of RFID and GPS technologies, as evaluated through experimentation, presents the opportunity of densely deploying low cost RFID tags with GPS-supported RFID readers to track construction materials. Park and Hashimoto [25] present a novel method using the read time of only a few number of passive HD RFID tags without any external sensors, signal strength measurement, or a vision system. The experimental results show that their method offers a modular and cost-effective way for servicing mobile robots in indoor environment, enabling the synchronized locational and orientational estimation of robots. $\mathrm{Li}$ and Becerik-Gerber [26] emphasize the significance of indoor location information in improving the utilization and maintenance of facilities. They review 21 research projects where RFID-based indoor location sensing (ILS) solutions were applied in the context of algorithm design, devices, test setup, and performance evaluation. A summary on the use of the proximity method and the underlying rationales in RFIDbased ILS is made, which indicates that no single solution satisfies the widespread deployment of RFID-based ILS.

Based on the RSSI, there are three better known localization algorithms, the lateration algorithm, the minimum maximum algorithm, and the ring overlapping circles algorithm [27, 28]. Papamanthou et al. [29] examine the RSSI measurement model for location estimation and provide the first detailed formulation of the probability distribution of the position of a sensor node. On the other hand, rangebased algorithms make use of the RSSI to estimate the distance between nodes. Then, different techniques, such as lateration [30], triangulation [31], or statistical inference [32], are used to estimate the position of strayed nodes with respect to the beacons. Unfortunately, RSSI-based ranging is severely affected by errors due to the unpredictable radio propagation behavior. Hence a RSSI positioning algorithm with microzoning is presented in the next section.

\section{RSSI Positioning Algorithm Based on Microzoning Method}

This section presents and examines the microzoning method which consists essentially of absolute received signal strength indication (RSSI) positioning algorithm on the basis of measuring the distance of tag from antennas base. In this 


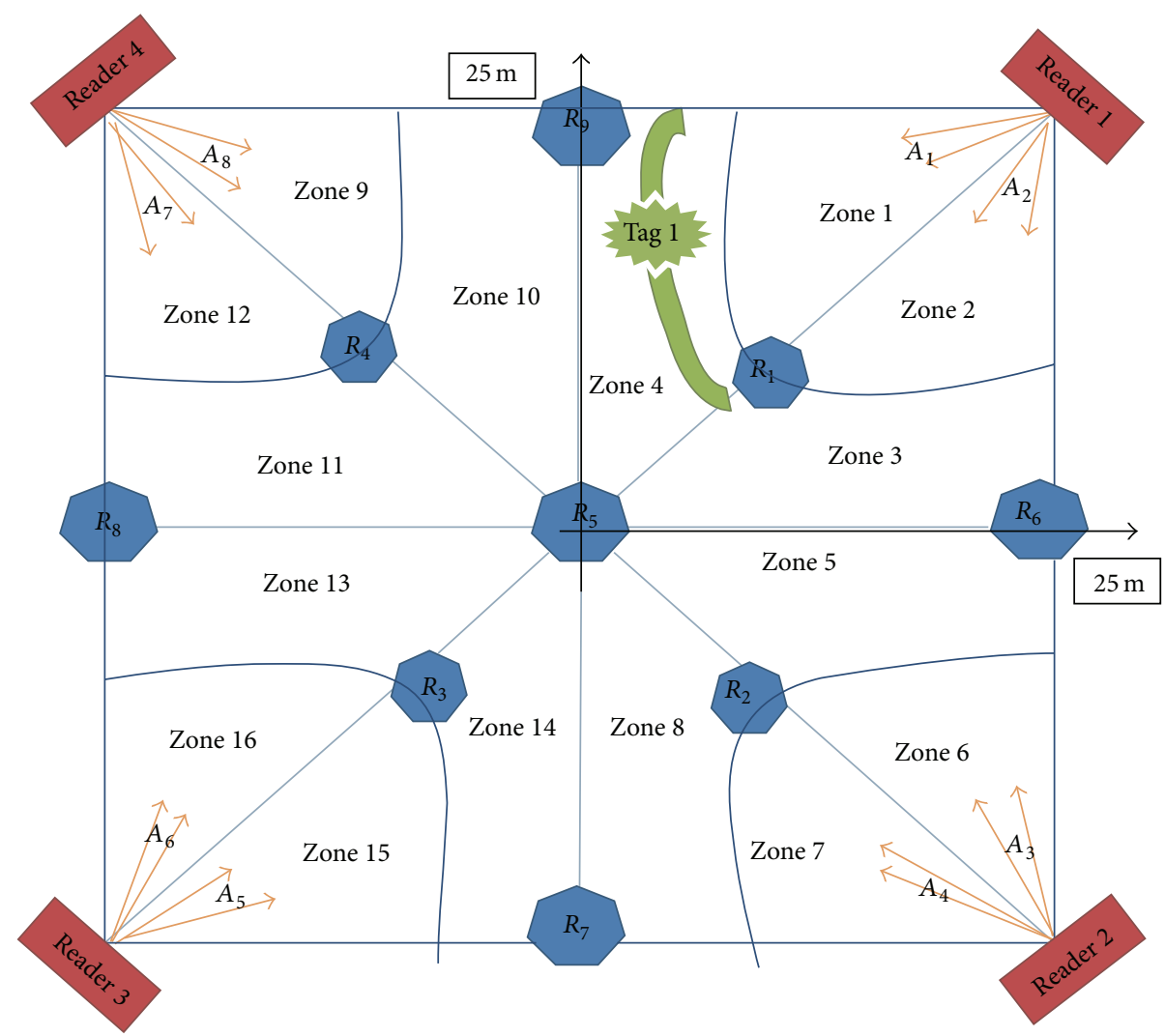

FIGURE 1: Demonstration of RSSI positioning algorithm based on microzones.

paper, we analyse and examine the effects of microzoning method on the performance of RFID tags. A system was set up whereby the RFID tags and antennas with the microzoning method were developed and studied. The performance of the tag antennas was studied with the practical read-range measurements. The aim of microzoning method is to locate the position of an RFID tag in the given area based on RSSI signals. In other words, this method was to measure the distance of tag from antennas using absolute RSSI. Within the algorithm, the position of the tag is estimated down to predefined microzones based on the reference tags. The signal strength of the tag is compared with that of the referenced tags, and therefore the relative position of the tag can be estimated. Figure 1 depicts the design of method and the layout of study using microzoning. A square region is divided into eight subzones, Zone $(i=1,2, \ldots 12)$. Nine reference tags $R_{j}(i=1,2, \ldots 9)$ are set in the square and four readers Reader $_{k}(k=1,2,3,4)$ are fixed at four canners. A tag which needs to be located is set in one of the microzones (see Figure 1).

The algorithm will be described using following parameters and variables.

$\left(A_{2 k-1}, A_{2 k}\right)$ : antenna pair, $k=1,2,3,4$,

$R_{j}$ : reference tag, $j=1,2, \ldots, 9$,

$R A_{j}$ : RSSI of the (target) tag from antenna $A_{j}$,

$R A_{i, j}$ : RSSI of the $i$ th reference tag from antenna $A_{j}$,
$(X, Y)$ : position of the tag,

$\left(x_{i}, y_{i}\right)$ : position of the $i$ th reference tag,

$\left(x_{j}^{\prime}, y_{j}^{\prime}\right)$ : position of the $j$ th antenna,

$d A_{j},(j=1,2, \ldots, 8)$ : Euclidean distance of the tag from the antennas using absolute RSSI

$$
d A_{j}=\sqrt{\left(X-x_{j}^{\prime}\right)^{2}+\left(Y-y_{j}^{\prime}\right)^{2}},
$$

$d R_{j},(j=1,2, \ldots, 9)$ : Euclidean distance of the reference tag from the antennas using absolute RSSI

$$
d R_{j}=\sqrt{\left(X-x_{j}\right)^{2}+\left(Y-y_{j}\right)^{2}} .
$$

The proposed algorithm is carried out in the following 4 stages.

Stage 1 (identify the quadrant). Identify which quadrant the tag belongs to by finding the reader with the best RSSI value from both the antenna pair by the following:

$$
\operatorname{RSSI}_{k}=\max \left\{R A_{2 k-1}+R A_{2 k}\right\},
$$

where $k=1,2,3,4$ and is corresponded to Zone $k$, respectively, for example, locating "Tag 1" as shown in Figure 1. The calculation of RSSI values of antennas is listed in Table 1. It is found that the tag is in Quadrant 1 (which includes 
TABLE 1: The calculation of locating “Tag 1."

\begin{tabular}{lcccc}
\hline$k$ & 1 & 2 & 3 & 4 \\
\hline$R A_{2 k-1}$ & -30 & -60 & -100 & -70 \\
$R A_{2 k}$ & -40 & -70 & -90 & -60 \\
$R A_{2 k-1}+R A_{2 k}$ & -70 & 130 & 190 & -130 \\
Quadrant & $\mathbf{1}$ & $\mathbf{2}$ & $\mathbf{3}$ & $\mathbf{4}$ \\
\hline
\end{tabular}

Zone 1, Zone 2, Zone 3, and Zone 4). Therefore, we depend on 2 antenna pairs to conclude if the tag is in one quadrant.

Stage 2 (identify subquadrant). Based on the differential RSSI readings from two antenna pairs in the identified quadrant, it can be found to which subquadrant the tag belongs to. For example, two antenna pairs in Quadrant 1 are $A_{1}$ and $A_{2}$. Since $A_{1}$ 's RSSI is greater than $A_{2}$ 's, the tag is in the subquadrant of $A_{1}$ (which includes Zone 1 and Zone 4).

Stage 3 (identify zone). Based on the relative readings between Tag 1 and the reference tags, it can be found which zone the tag belongs to. For example, suppose the RSSI of reference tags from antenna $A_{1}$ are as follows $R A_{r 1,1}=-25, R A_{r 1,9}=$ -40 , and $R A_{r 1,5}=-45$; then it can be inferred that the tag is in Zone 4 , that is, between $R_{1}$ and $R_{9}-R_{5}$.

Stage 4 (identify approximate distance). Based on the relative readings between the reference tags and the actual tag using the distance of the reference tags from the antenna, the approximate distance of a tag from the antenna can then be determined by (4)

$$
d=10^{(-B-R A) / 10 n,}
$$

where $R A$ denotes the RSSI value of the tag from antenna $A$, $n$ is a signal propagation constant or exponent, $d$ is a distance from the tag to the reference tag, and $B$ is the received signal strength at $1 \mathrm{~m}$ distance.

For example, the RSSI of Tag 1 from antenna $A_{1}$ is -35 , and the reference $\operatorname{tag} R_{1}$ is at a distance $6 \mathrm{~m}$. Then it can be inferred that Tag 1 is in Zone 4 at a distance of approximately $10 \mathrm{~m}$ from the antenna $A_{1}$ (green patch).

Then the approximate position coordinate $(X, Y)$ of the tag can be identified by (1) and (2).

It should be noted that the accuracy of results from Stage 3 and Stage 4 is subject to the issues caused by null effect of radio signals. The null effect can be explained that due to wave nature of radio frequencies, a tag can show a low RSSI value than what it is expected to show at a certain distance. For example, if a tag is supposed to show $-30 \mathrm{dbm}$ for a distance of 20 meters, due to surface reflection, it might show $-60 \mathrm{dbm}$ for the same 20 meters. A potential solution to overcome the problem due to the null effect of radio signals can be by placing a second reader (antenna pair) a few meters above the planned reader (antenna pair) in the same direction; we could take the best RSSI signal out of two readers for the same tag.

The following devices are used in the experiment.

(i) Intelleflex FMR reader $\times 4$,

(ii) Intelleflex antenna $12^{\prime \prime}$ patch antenna $\times 8$ pair,

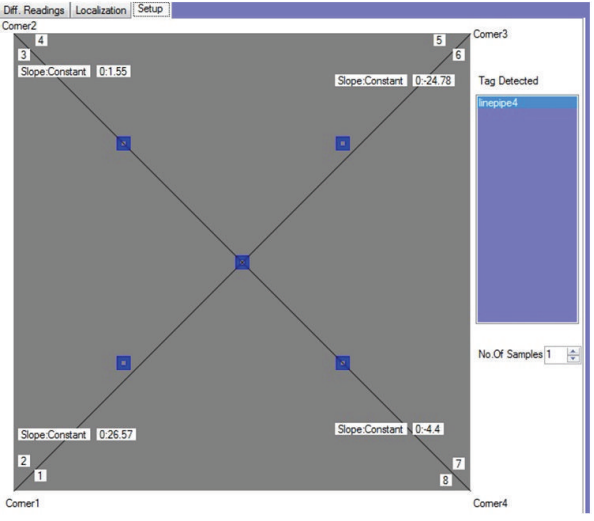

Figure 2: Graphical interface of the tracked items.

\begin{tabular}{|c|c|c|c|c|}
\hline Diff. Readings Localization & Setup & & & \\
\hline Tag & Location X & Location $Y$ & Timestamp & Corner \\
\hline linepipe4 & 18 & 6 & 05/04/2012 08:59:01 AM & corner1 \\
\hline linepipe4 & 18 & 6 & 05/04/2012 08:59:01 AMI & corner2 \\
\hline linepipe4 & 18 & 6 & 05/04/2012 08:59:01 AM & corner3 \\
\hline linepipe4 & 18 & 6 & 05/04/2012 08:59:01 AM & corner 4 \\
\hline
\end{tabular}

FIGURE 3: RFID application on the computer that lists the location $(X, Y)$ and timestamp of the tracked item.

(iii) Intelleflex general purpose tags $\times 10(9$ reference + 1 blind). Suggested tags for reference tags: nonmetal tags,

(iv) some snapshots: the following figures demonstrate an example of the graphical interface of the tracked items (Figure 2), the RFID application on the computer that lists the location $(X, Y)$ and timestamp of the tracked item (Figure 3), and RFID application on the computer that lists differential RSSI, angle, and timestamp of the tracked item (Figure 4).

\section{Experimentation}

Field experimentation was conducted in this paper. The test setup, configuration, and conclusion for the test are discussed in this section. The aim of the experiment is to find the maximum range of tag detection and to find the relationship between absolute RSSI (signal strength) and distance of tag from antennas. Various factors affecting the relation between signal and distance are listed as follows:

(i) height of tag,

(ii) angle of tag,

(iii) multipath loss or gain.

Testing sites are as follows:

(1) Packard Street, Joondalup,

(2) Elcar Park (see Figure 5),

(3) Heathridge Park (see Figure 6). 


\begin{tabular}{|c|c|c|c|c|c|}
\hline Diff. Readings & Localization & Setup & & & \\
\hline Tag & & Corner & Diff. RSSi & Angle & Timestamp \\
\hline linepipe4 & & corner1 & -41 & 26.57 & 05/04/2012 08:59:01 AM \\
\hline linepipe 4 & & corner2 & -46.5 & 1.55 & 05/04/2012 08:59:01 AM \\
\hline linepipe 4 & & corner3 & -46.38 & -24.78 & 05/04/2012 08:59:01 AM \\
\hline linepipe 4 & & corner 4 & -46.25 & -4.4 & 05/04/2012 08:59:01 AM \\
\hline
\end{tabular}

FIgURE 4: RFID application on the computer that lists differential RSSI, angle, and timestamp of the tracked items.
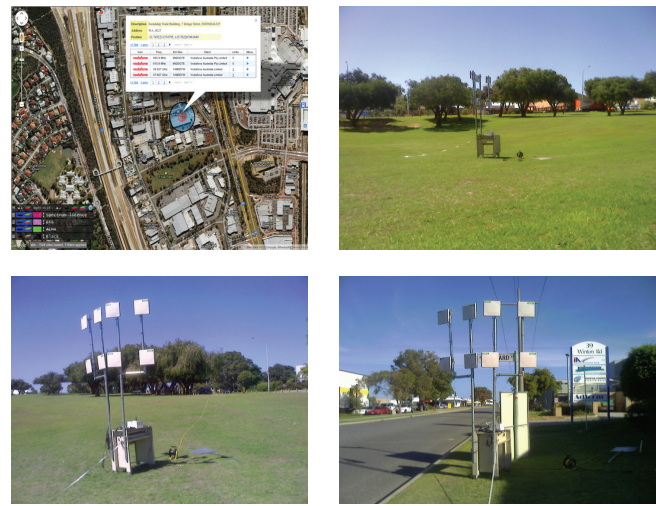

Figure 5: Elcar Park.

Equipment used is as follows:

(i) Intelleflex reader: 1 ,

(ii) $12^{\prime \prime}$ patch antenna: 2 pairs,

(iii) metal Mounting Tag: 1 for location purpose,

(iv) custom application software that would query two antenna ports and log the results in a csv file with the below given format "tagid, description, port, signal strength."

Test setup is as follows:

(i) two pairs of antennas are connected to a single reader. The first pair of antennas is fixed at $2.5 \mathrm{~m}$ above the ground, and the second pair of antenna is fitted $3.5 \mathrm{~m}$ above the ground,

(ii) all the four antennas are pointed in a single plane, in same direction, perpendicular to the ground,

(iii) the metal tag used for location is mounted on a metal plate and held at a height of $1.5 \mathrm{~m}$ on a steel pole.

\section{Data Collection and Results Analysis}

In the test site 1 , the tag is read along over a linear distance every $10 \mathrm{~m}$ by two pairs of antennas with one pair at $2.5 \mathrm{~m}$ height and the other at $3.5 \mathrm{~m}$ height. According to Figure 7, this graph shows that the tags were detected up to a range of $130 \mathrm{~m}$ in the centre line. When the bottom antenna goes to a null at $30 \mathrm{~m}$, the top antenna provides a reliable reading; when the top antenna goes to a null at $40 \mathrm{~m}$, the bottom antenna provides a reliable reading. Thus a reliable detection and signal strength can be obtained from nearly all the points by using spatial diversity.
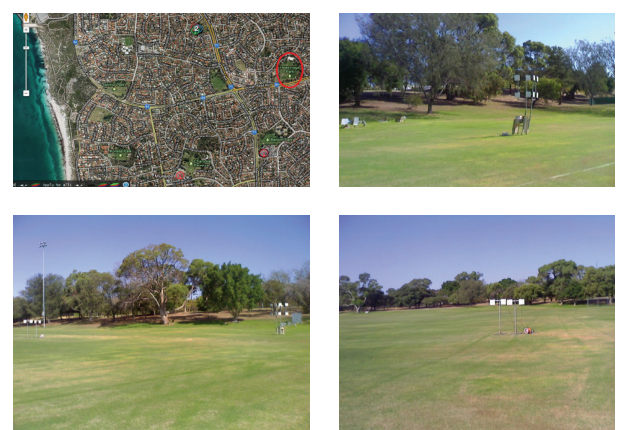

FIgURe 6: Heathridge Park.

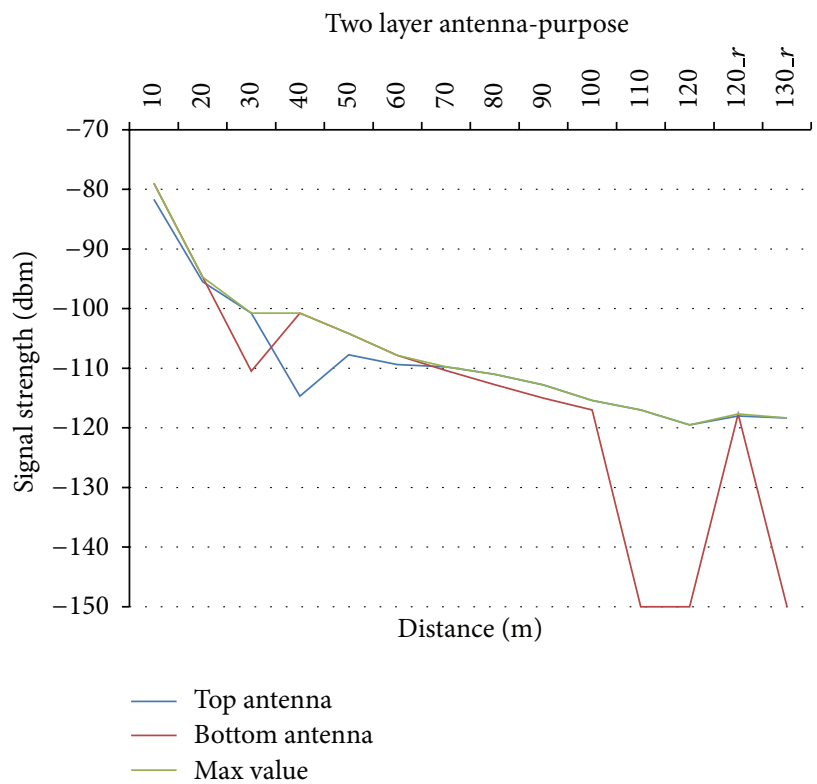

FIGURE 7: Long range detection at test site 1.

This test was conducted over a sealed road with objects (cars) on the sides. The RFID tags were detected up to a range of $120 \mathrm{~m}$ in the centre line. It is possible that the objects on the side of the road could serve as a magnifying tunnel and help increase the range of detection. Signal magnification caused due to objects presented along the signal path may boost the detection range.

In the test site 2 with dual layer antenna test, tag moved along a straight line from $10 \mathrm{~m}$ to $40 \mathrm{~m}, 2 \mathrm{~m}$ at a time. According to Figure 8, the signal strength does not vary consistently with the distance for one antenna pair. Also, there are various nulls, which indicate that the tags may not be detected in many instances. However, by considering the maximum of two antenna values, tags can be detected and valid signal strength be measured at all instances.

Tag moved along centre line from $10 \mathrm{~m}$ to $100 \mathrm{~m}, 10 \mathrm{~m}$ at a time. According to Figure 9, it is observed that the tags were not detected between $50 \mathrm{~m}$ and $90 \mathrm{~m}$. After analyzing the park with the help of a spectrum analyzer, the major reason for this is traced back to the presence of strong radio interference in the region, due to a cell phone tower in the very close 


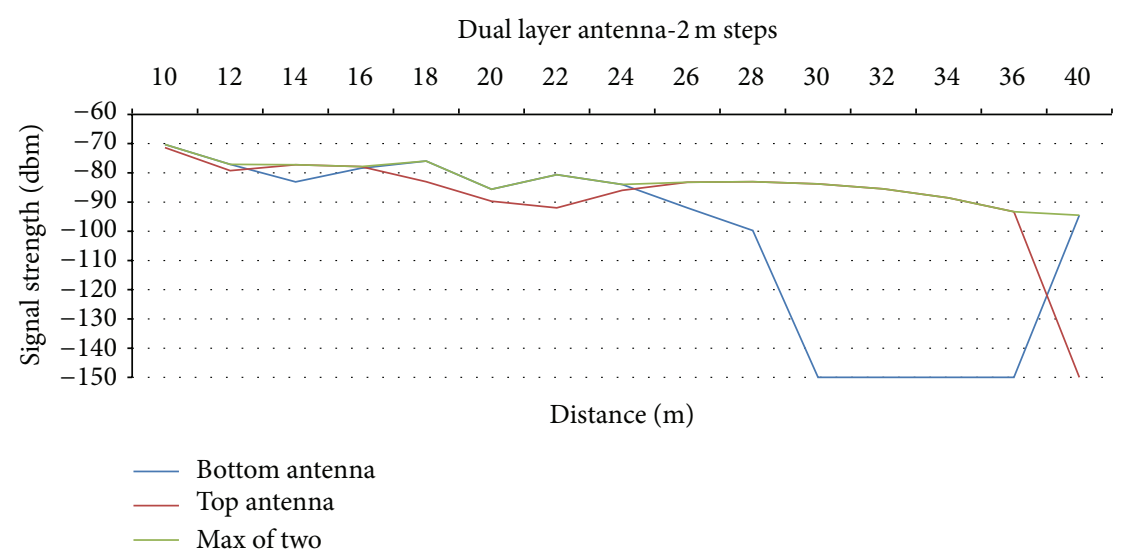

Figure 8: Dual layer antenna test $-2 \mathrm{~m}$ step.

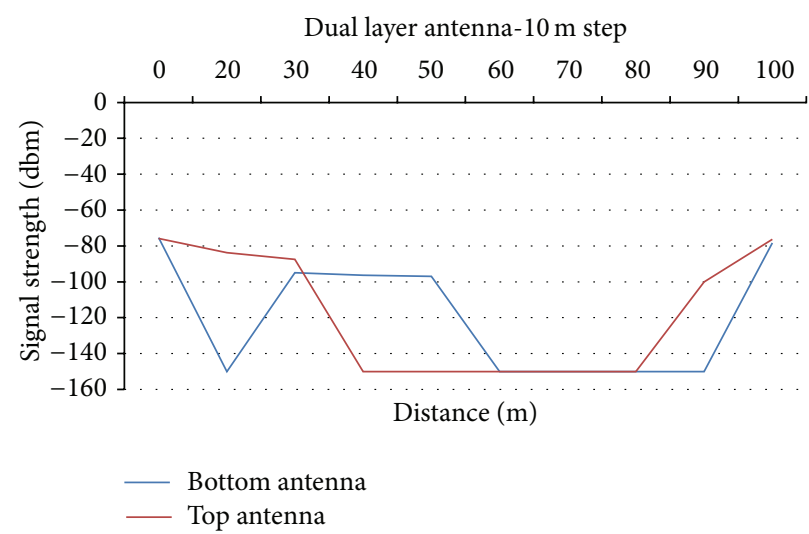

FIGURE 9: Long range detection at venue 2.

vicinity of the test site. Since the cell phone tower was sending signals in $950 \mathrm{MHz}$ frequency range whose strength was as strong as $-30 \mathrm{dBm}$, they were causing interference to the RFID system.

In test site 3, according to Figure 10, the bottom antenna shows reliable readings; however, the top antenna does not show a reliable reading due to the presence of multiple nulls. Thus spatial diversity of antennas will help reliably detect tags at all distances. Location 1 had object influence and Location 2 had radio frequency interference; therefore Location 3 was chosen to be free from both influences. An open park was verified free of radio interferences with the help of a spectrum analyzer and used for rest of the study. In this location, a range of $110 \mathrm{~m}$ was achieved.

\section{Conclusions}

This paper analysed and examined the effects of microzoning method on the performance of RFID tags. This experimental design aimed at demonstrating the proof of concept in a specified area of zone. The experimentation was conducted based on the proposed design and the test results were promising and showing that the proposed tag positioning (triangulation) concept is feasible (e.g., tags were detected up to a range of $130 \mathrm{~m}$ in the centre line). It is observed that the error is much less for tags closer to the centre and slightly higher for tags closer to the edge. Still the error is found to be considerably less than anticipated. The test results were positive with very low error rate. It is proved that spatial diversity of antennas (two layers of antenna, at different heights) could help reliably detect tags at all distances (up to the maximum range) to overcome the loss in signal strength due to multipath loss.

A significant discovery from Trials 1, 2, and 3 is the presence of "nulls" in the radio propagation, due to multipath loss. As a result of nulls, the RSSI value drops considerably even in short distances. After analyzing the test results, it was confirmed that absolute RSSI cannot be used for calculating the distance of a tag from an antenna.

Further tests need to be conducted to test different tag positions at different locations in square area. Moreover, tests should also be conducted with tags at various heights from the ground. As all these studies have been conducted with no obstacles in place at the current stage, the major work in future may focus on studying how this concept is applicable when obstacles are introduced in place. A lot of challenges 


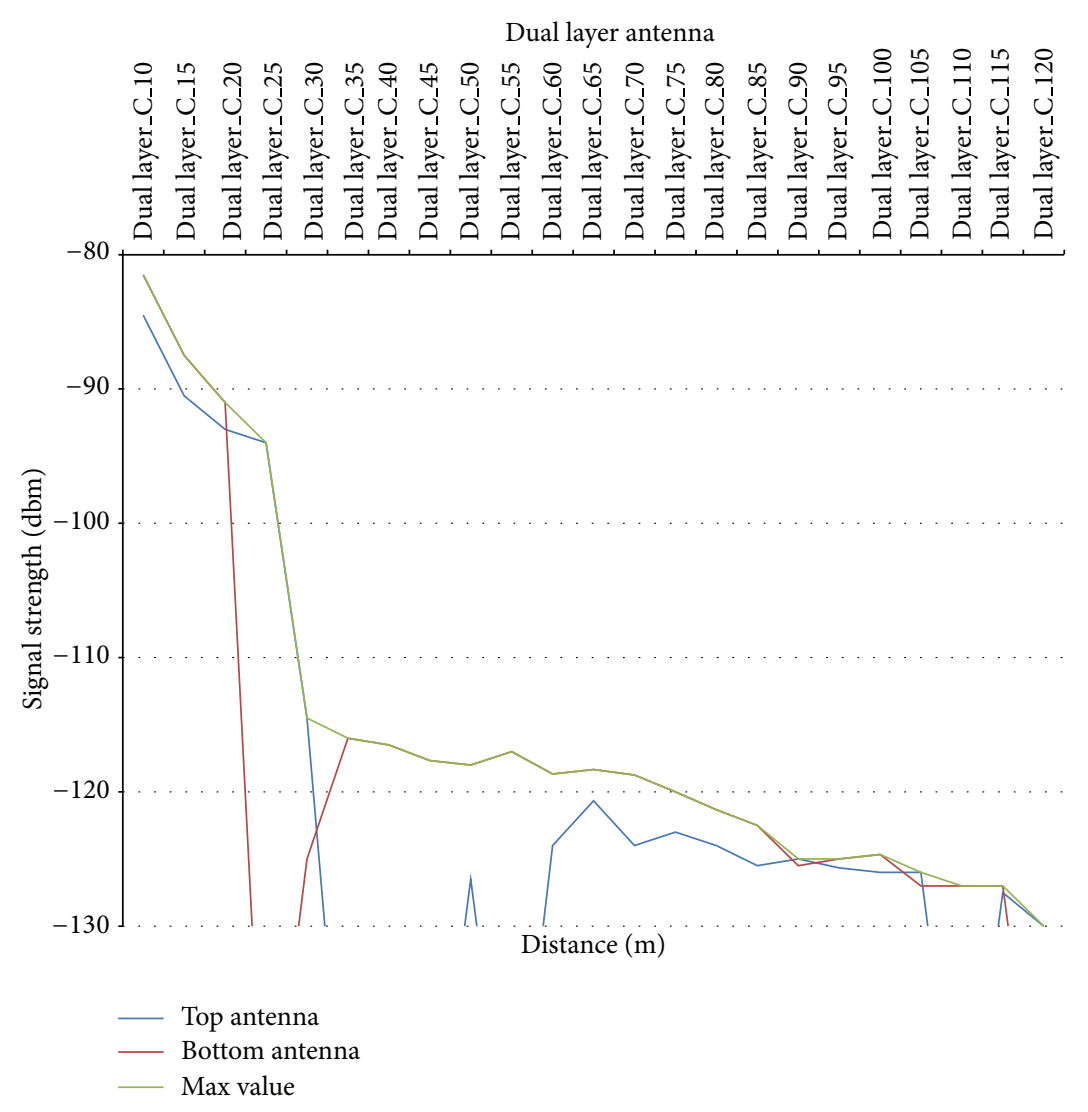

FIGURE 10: Long range detection at test site 3.

are expected in a larger zone as the accuracy of RFID system is expected to drop considerably with the distance increase. Moreover, a larger region may have a considerable path loss and hence it may be necessary to use spatial diversity (two layers of antennas). For integrating the four $X$ and $Y$ coordinates of a tag that were derived from four different corners (rather than averaging), more sophisticated methods like statistical analysis or information theories can be used to get better results.

\section{Conflict of Interests}

The authors declare that there is no conflict of interests regarding the publication of this paper.

\section{Acknowledgments}

The work presented in this paper was initiated by $\mathrm{Mr}$. Martijn Truijens, the Lean Construction Technology Advisor, Woodside Energy Limited (WEL), as part of the Project Echo Construction Research initiative. Also, part of this research was supported under Australian Research Council Linkage Project scheme (project name: Transforming LNG Plant Construction Productivity through Mobile Computing, Project no. LP130100451).

\section{References}

[1] G. Demiralp, G. Guven, and E. Ergen, "Analyzing the benefits of RFID technology for cost sharing in construction supply chains: a case study on prefabricated precast components," Automation in Construction, vol. 24, pp. 120-129, 2012.

[2] J. F. Alicot, S. R. Maitin, R. F. Devoe, and D. E. Jones, "Distributed Radio Frequency Identification Reader," EP Patent 2, 070, 000, 2011.

[3] A. M. Barker, G. R. Hanson, A. K. Sexton, J. Jones, E. B. Freer, and A. L. Sjoreen, "An active RFID Accountability System (RAS) for constrained wireless environments," in Proceedings of the Future of Instrumentation International Workshop (FIIW'11), pp. 25-27, IEEE, 2011.

[4] S. Nainan, R. Parekh, and T. Shah, "RFID technology based attendance management system," Evolution, vol. 10, p. 11, 2013.

[5] Intelleflex Corporation, "White Paper on 9 Key Points of Differentiation, Comparing Intelleflex Technology and Active RFID," 2011.

[6] R. Angeles, "RFID technologies: supply-chain applications and implementation issues," Information Systems Management, vol. 22, no. 1, pp. 51-65, 2005.

[7] T. M. Ruff and D. Hession-Kunz, "Application of radiofrequency identification systems to collision avoidance in metal/nonmetal mines," IEEE Transactions on Industry Applications, vol. 37, no. 1, pp. 112-116, 2001. 
[8] Y. S. Chang, M. G. Son, and C. H. Oh, "Design and implementation of RFID based air-cargo monitoring system," Advanced Engineering Informatics, vol. 25, no. 1, pp. 41-52, 2011.

[9] X. Qu, L. T. Simpson, and P. Stanfield, "A model for quantifying the value of RFID-enabled equipment tracking in hospitals," Advanced Engineering Informatics, vol. 25, no. 1, pp. 23-31, 2011.

[10] S. Hsi and H. Fait, "RFID enhances visitors' museum experience at the Exploratorium," Communications of the ACM, vol. 48, no. 9, pp. 60-65, 2005.

[11] J.-L. Hou and T.-G. Chen, "An RFID-based Shopping Service System for retailers," Advanced Engineering Informatics, vol. 25, no. 1, pp. 103-115, 2011.

[12] P. Jones, C. Clarke-Hill, D. Comfort, D. Hillier, and P. Shears, "Radio frequency identification in retailing and privacy and public policy issues," Management Research News, vol. 27, pp. 46-56, 2004.

[13] B. Eckfeldt, "What does RFID do for the consumer?" Communications of the ACM, vol. 48, no. 9, pp. 77-79, 2005.

[14] S. Abdoli, "RFID application in municipal solid waste management system," International Journal of Environmental Research, vol. 3, no. 3, pp. 447-454, 2009.

[15] W. C. Stone, L. Pfeffer, and K. Furlani, "Automated part tracking on the construction job site," in Proceedings of the 4th International Conference and Exposition/Demonstration on Robotics for Challenging Situations and Environments, pp. 96103, March 2000.

[16] E. J. Jaselskis and T. El-Misalami, "Implementing radio frequency identification in the construction process," Journal of Construction Engineering and Management, vol. 129, no. 6, pp. 680-688, 2003.

[17] J. Yagi, E. Arai, and T. Arai, "Parts and packets unification radio frequency identification (RFID) application for construction," Automation in Construction, vol. 14, no. 4, pp. 477-490, 2005.

[18] X. Wang, P. E. D. Love, M. J. Kim, C. S. Park, C. -P. Sing, and L. Hou, "A conceptual framework for integrating building information modeling with augmented reality," Automation in Construction, vol. 34, pp. 37-44, 2013.

[19] Z. Ren, C. J. Anumba, and J. Tah, "RFID-facilitated construction materials management (RFID-CMM) - a case study of watersupply project," Advanced Engineering Informatics, vol. 25, no. 2, pp. 198-207, 2011.

[20] A. Motamedi, R. Saini, A. Hammad, and B. Zhu, "Rolebased access to facilities lifecycle information on RFID tags," Advanced Engineering Informatics, vol. 25, no. 3, pp. 559-568, 2011.

[21] C. Cho, H. Choo, and I. Park, "Broadband RFID tag antenna with quasi-isotropic radiation pattern," Electronics Letters, vol. 41, no. 20, pp. 1091-1092, 2005.

[22] J. R. Smith, K. P. Fishkin, B. Jiang et al., "RFID-based techniques for human-activity detection," Communications of the ACM, vol. 48, no. 9, pp. 39-44, 2005.

[23] J. Zhou and J. Shi, "A comprehensive multi-factor analysis on RFID localization capability," Advanced Engineering Informatics, vol. 25, no. 1, pp. 32-40, 2011.

[24] J. Song, C. T. Haas, and C. H. Caldas, "A proximity-based method for locating RFID tagged objects," Advanced Engineering Informatics, vol. 21, no. 4, pp. 367-376, 2007.
[25] S. Park and S. Hashimoto, "An intelligent localization algorithm using read time of RFID system," Advanced Engineering Informatics, vol. 24, no. 4, pp. 490-497, 2010.

[26] N. Li and B. Becerik-Gerber, "Performance-based evaluation of RFID-based indoor location sensing solutions for the built environment," Advanced Engineering Informatics, vol. 25, no. 3, pp. 535-546, 2011.

[27] X. Nguyen and T. Rattentbury, "Localization algorithms for sensor networks using RF signal strength," Tech. Rep., University of California at Berkeley, 2003.

[28] I. F. Akyildiz, W. Su, Y. Sankarasubramaniam, and E. Cayirci, "Wireless sensor networks: a survey," Computer Networks, vol. 38, no. 4, pp. 393-422, 2002.

[29] C. Papamanthou, F. P. Preparata, and R. Tamassia, "Algorithms for location estimation based on rssi sampling," in Algorithmic Aspects of Wireless Sensor Networks, pp. 72-86, Springer, Berlin, Germany, 2008.

[30] A. Savvides, H. Park, and M. B. Srivastava, "The n-hop multilateration primitive for node localization problems," Mobile Networks and Applications, vol. 8, no. 4, pp. 443-451, 2003.

[31] A. Savvides, H. Park, and M. B. Srivastava, "The bits and flops of the n-hop multilateration primitive for node localization problems," in Proceedings of the 1st ACM International Workshop on Wireless Sensor Networks and Applications, pp.112-121, ACM, September 2002.

[32] N. Patwari, A. O. Hero III, M. Perkins, N. S. Correal, and R. J. O'Dea, "Relative location estimation in wireless sensor networks," IEEE Transactions on Signal Processing, vol. 51, no. 8, pp. 2137-2148, 2003. 


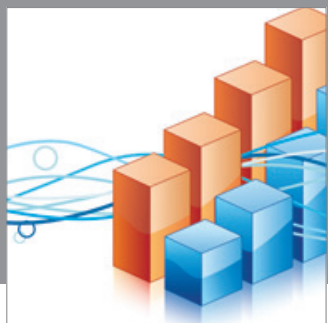

Advances in

Operations Research

mansans

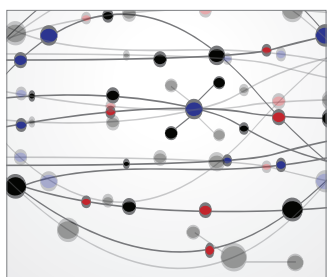

The Scientific World Journal
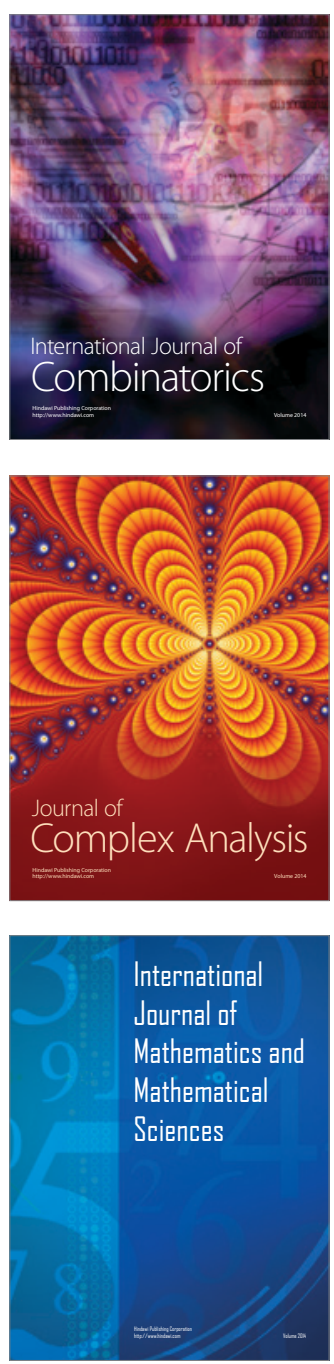
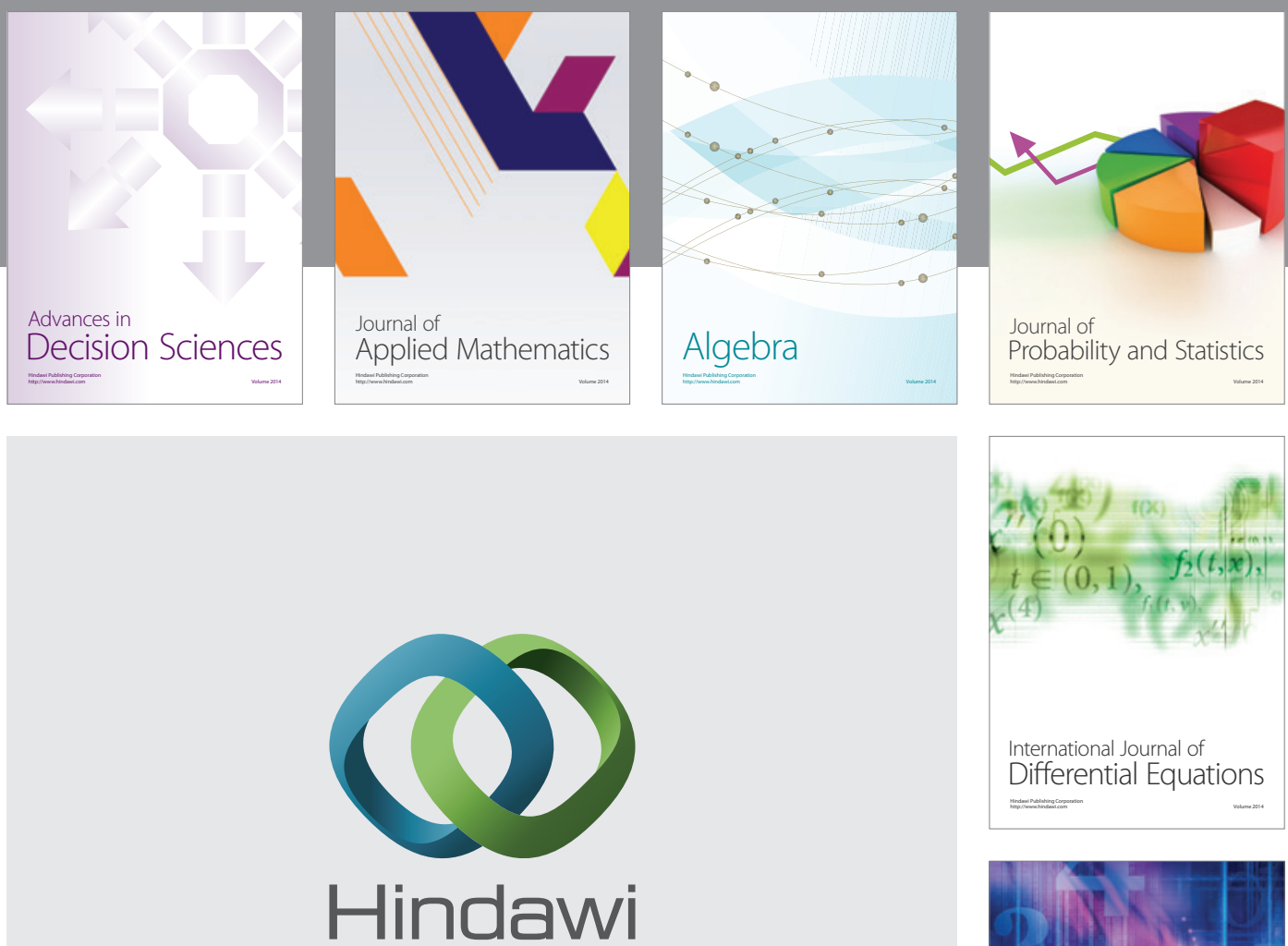

Submit your manuscripts at http://www.hindawi.com
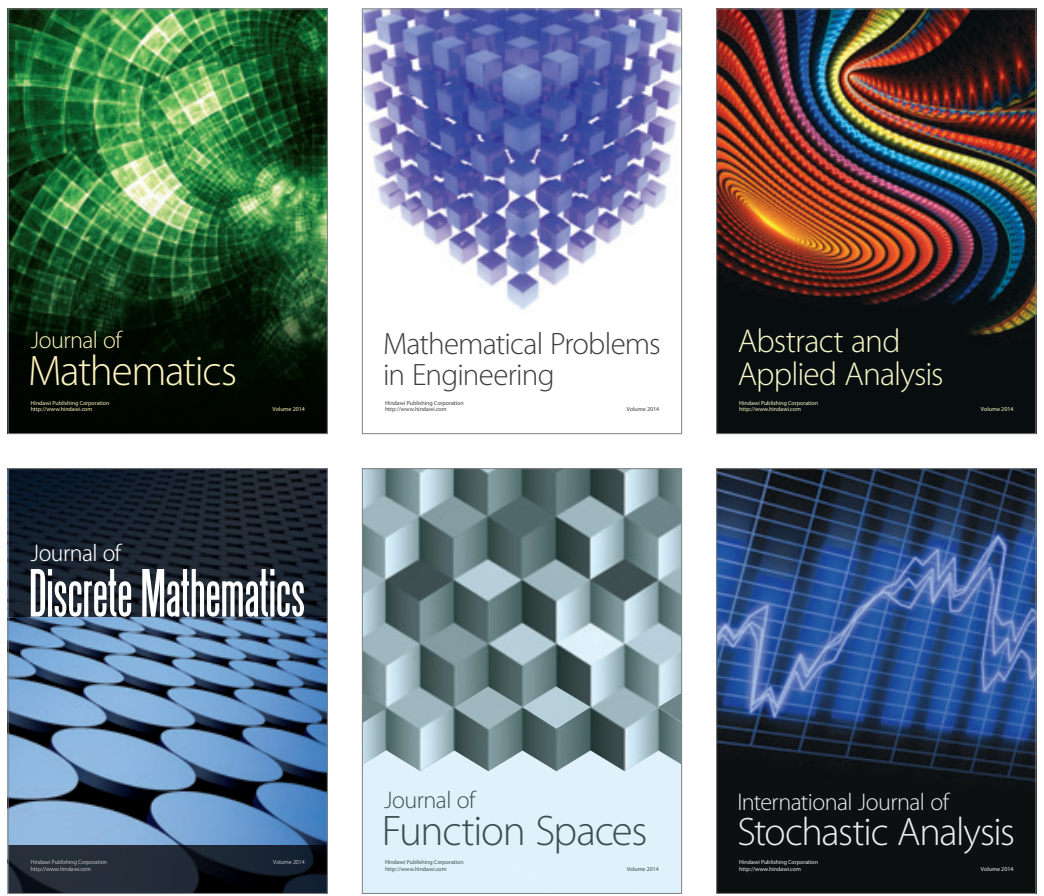

Journal of

Function Spaces

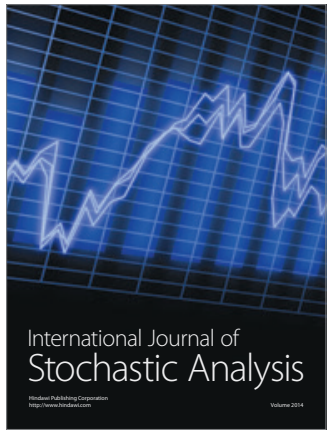

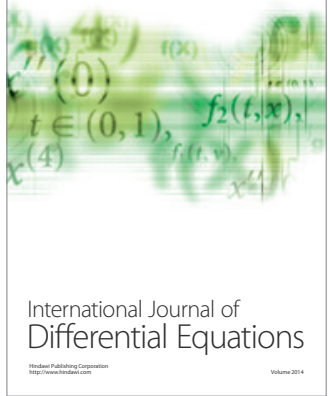
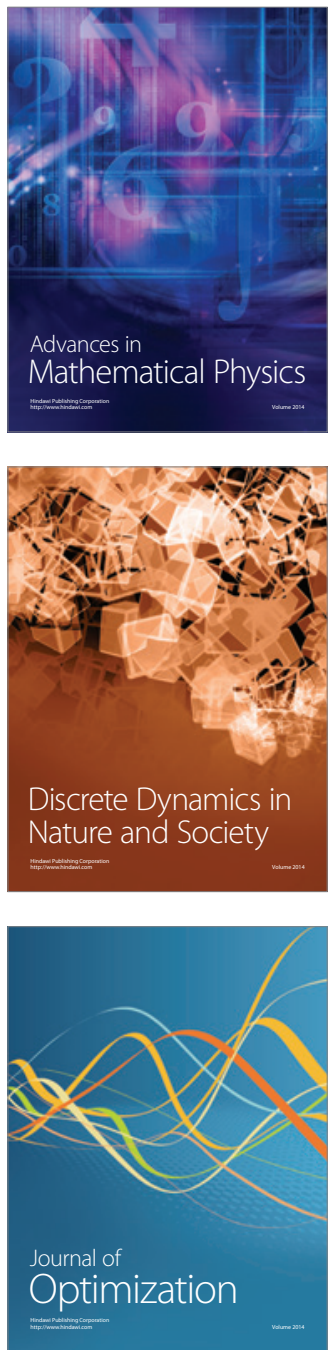